\title{
Staying alert \\ The wild new world of current awareness services
}

$\mathbf{T}$ oday we all know how important it is to keep up with the ever-changing information world. But not only do we need to stay current ourselves, we also need to help our patrons do the same in their elds. And since our patrons are diverse groups with widely ranging interests, that $\mathrm{s}$ no small challenge.

Luckily, as the quantity of information has exploded, so have various methods to track it. It would be nice if there were one single service that did everything, but that hasn t happened, and isn t likely to happen any time soon. Since current awareness today really requires several different tools and approaches, librarians need to help patrons nd the services that best meet their needs.

\section{In the beginning ...}

Current awareness (sometimes called selective dissemination of information or SDI) has always been a concern for professionals. The development of modern methods is often traced to the 17th century, with the rst scholarly societies and their publications, such as the Royal Society of London. These arose when the scientists of the day found that meetings, books, personal contacts, and correspondence were no longer adequate. ${ }^{1}$

In the 1830s, abstracting journals were created to notify people of recent publications, and cumulative indexes soon followed to provide ways of searching the existing literature. A century or so later, however, the rapid growth of technology (especially during and after the two World Wars) led to these abstracting and indexing services becoming unwieldy.

Computers entered the scene in the 1960s, but, despite the existence of a few edgling services, librarians still had primary responsibility for routing current information to patrons. In his 1979 book on current awareness services, D. A. Kemp outlines routines and methods that are onerous, labor-intensive, and exacting. ${ }^{2}$

Even later, McKimmie described a New Mexico State University program that, in 1991, offered current awareness services to 18 science departments. A profile of each researcher was run against Current Contents diskettes weekly, and relevant citations were delivered to the faculty members. Users were satisfied and found the majority of citations relevant, ${ }^{3}$ but it was certainly a lot of work for the librarian.

Information continued to proliferate through the 1990s. Librarians found various ways to address this, most of them still quite labor-intensive. They devised systems to nd, abstract, and pass on to patrons relevant information; for example, by copying tables of contents and forwarding them or compiling lists of articles. In most cases the librarian vetted and distilled the information, and then physically copied it or telephoned patrons to notify them that material of interest was available. ${ }^{4}$

Dorothy Barr is information literacy librarian at University of Massachusetts Medical School, e-mail: Dorothy. Barr@umassmed.edu

๑ 2006 Dorothy Barr 
Gradually, computers took over much of the drudgery, but librarians still played a major role in organizing and disseminating information.

There were also commercial services. In 1995 eWatch Internet Clipping Service was available for $\$ 295$ per month plus $\$ 2$ per clip. ${ }^{5}$ ISI in 1999 offered Current Contents Desktop, an electronic application of an old library standby. ${ }^{6}$ But such commercial services were most often used in the private sector, as the costs were prohibitive for most academic institutions.

By the late 1990s, however, there were at least some current awareness services available free through the Web, and their growing importance was being recognized. Timely access to appropriate, quality information is often associated with power, progress and prosperity. ${ }^{7}$ But that same year Greg Notess commented that [t]he available Internet current awareness services are still rst generation tools. ${ }^{8}$

\section{Today ...}

Although current awareness services have come a long way in just a few years, information overload is still a major concern. Alerting services are very appealing but can easily end up inundating users with far too much information. Current awareness ... is a classic with all its imperfections we can $t$ live without it proposition .... ${ }^{9}$

A couple of the most obvious services are:

News Alert Services. Recently, more and more free services have come on the scene. For instance, it $s$ very easy to set up e-mail alerts from news sources, such as the New York Times and CNN.

Tables of Contents (TOC). For more speci $\mathrm{c}$ information, TOCs are very popular and easy to set up. Publishers in particular have been quick to offer these as a way to tout their products, keeping current subscribers happy and luring new ones. TOCs are quick and easy, often cover multiple journals or offer additional functionality, ${ }^{10}$ and are almost always free. For some people such as the academician who is not doing research, but who has favorite journals and wants to keep up with new developments in the eld TOCs alone may be suf cient.

Other auto-alerts come in many varieties. You can get topic alerts by e-mail from many publishers, databases, and even from Google and other search engines. You can get citation alerts, from sites such as science.gov and other government agencies, notifying you when particular articles are cited. The list goes on and on.

But all this means yet more e-mail in the already over owing inbox. Luckily, there is a solution, one which is becoming increasingly common and one with which librarians should all be familiar.

\section{Enter the feed}

Feeds sound geeky and intimidating, but actually they re very simple. More and more Web sites offer them as a way of letting you know when their sites have been updated, so you don t have to keep visiting them. Instead of using e-mail, the information is sent to a central place where you go to read all your feeds at your leisure. The result is fewer e-mails and less time spent checking individual Web sites.

RSS (Really Simple Syndication) and Atom are the most common feeds, but there are others. To use them you need a feed reader or aggregator a piece of software that collects information from sites that have feeds. There are many different aggregators. With some of them you download a very small program; with others you visit a Web site. Once you have an aggregator, you go to favorite sites and look for feed buttons ( RSS or XML for example). Clicking on the button takes you to a page with a URL that you simply copy and paste into your aggregator (look for the add button or something similar). The aggregator then goes out regularly to collect the feeds that you have chosen, and then it groups them together for you to peruse at your leisure. All you have to do is go to your aggregator and look at the results; they are generally 
presented with brief descriptions, and you can click on a link if you wish to read the whole article.

So there are three easy steps to using RSS:

1. choose a feed reader (download, Web-based);

2. nd a feed; and

3. add the feed to the feed reader. ${ }^{11}$

And, really, it s just about that easy.

Rather surprisingly, not everyone has jumped on the feeds wagon. Gillian Byrne notes that while RSS is the current buzz topic and is wildly popular among bloggers, techies and information professionals, [it] has yet to make a dent in the public consciousness. ${ }^{12}$ And Kevin Broun noted that at the National Cancer Institute they found that few of their patrons had heard of the technology, and none had installed aggregators. So the librarians set up their own system of daily updates. ${ }^{13}$ Although this might work within speci c subject areas, it is very laborintensive for librarians and really isn t practical for colleges and universities with patrons with diverse interests.

\section{Other approaches}

Although feeds work really well for keeping up with news, aggregators don $t$ discriminate, and you can t ef ciently narrow your searches; what you get is everything that appears on the site. To keep up with new research, different, more sophisticated systems may be available.

Different elds use different approaches. For example, PubMed s My NCBI offers users a way to not only save search strategies, but to get e-mail alerts about new articles on a regular basis. Many clinicians and researchers have been slow to take advantage of My NCBI, however, and this is surely an area where librarians can help.

Other disciplines use other approaches preprints, e-zines, electronic newsletters, blogs, and electronic lists, for example. New tools, such as social bookmarking, offer novel ways to get and organize information. Overall, however, there is no one system that does it all, and combining several approaches is the safest way of ensuring that you and your patrons keep up ef ciently with what $s$ new in your elds.

\section{Conclusions}

There is nothing new about current awareness services; what is new is the technologies. ${ }^{14}$ There are many different approaches, and the number and diversity of tools can be overwhelming, so it $s$ necessary to be selective, both for oneself and in helping patrons. Cohen suggests constantly looking for new and better resources, but at the same time, purging those that are no longer useful. ${ }^{15}$ Otherwise it would be easy to use so many diverse tools that managing them ef ciently would be impossible.

Cohen notes that there are two reasons for librarians to keep current: . . . monitoring ongoing news and resources for their profession and locating useful resources for their patrons ... If librarians are able to show their patrons that they are hip and know and understand the current developments on the [W]eb, they will be seen as cutting edge. ${ }^{16}$ If we are to be information experts, we must be as familiar with all of these [resources] as possible. ${ }^{17}$ And if we aren t comfortable with technologies, we can hardly help our patrons to use them effectively.

Whatever the eld, we should be able to help our patrons choose and use the current awareness tools that will be most useful for them. Since those tools are constantly changing, our challenge is to keep up, not only with actual information but also with the evolving methods of tracking it.

\section{Notes}

1. D. A. Kemp, Current awareness services. (London: Clive Bingley, 1979): 13.

2. Ibid., 14.

3. T. McKimmie, 1994. Evaluation of a current awareness service in an academic library, New Mexico State University, Eric Document 374820: 10.

4. Kenneth McMahon, Current awareness services, Computers in Libraries 15, no. 4 (1995): 7980. 
5. Anonymous, Internet current awareness service, Searcher 3, no. 10 (1995): 8.

6. Anonymous, ISI releases newest version of current contents for the desktop, Information Today 16, no. 5 (1999): 32.

7. Ina Fourie, Empowering users: Current awareness on the internet, The Electronic Library 17, no. 6 (1999): 379.

8. Greg R. Notess, Internet current awareness. Online 23, no. 2 (1999): 75 .

9. U. de Stricker, Keep me posted ... but not too much : Challenges and opportunities for STM current-awareness providers, Searcher 10, no. 1 (2002): 5259.

10. Bonnie Darves, E-alerts: All the rage, Medicine on the Net 10, no. 10 (2004): 15.

11. Jay Bhatt, Peggy Dominy, and Andrew Wheeler. Keep up-to-date using subject speci c blogs, RSS feeds, and listservs.
(Poster presented at SLA 2005 Conference, Toronto, Ontario.)

12. Gillian Byrne, RSS and libraries: Fad or the future? Feliciter 51, no. 2 (2005): 6263.

13. Kevin Broun, New dog, old trick: Alerts for RSS feeds, Library Journal, Summer NetConnect Supplement (July 2004): 18.

14. Roy Tennant, Feed your head: Keeping up by using RSS, Library Journal 128, no. 9 (2003): 30.

15. Steven M. Cohen, Eight steps for keeping current, Knowledge Quest 33, no. 1: 4041 .

16. Stephen Cohen, Keeping current: $A d-$ vanced internet strategies to meet librarian and patron needs (Chicago: American Library Association, 2004).

17. Rachel Wadham, Rich site summary (RSS), Library Mosaics 16, no. 1 (2005): 25. 22

\title{
University of OWahoma Libraries presents
}

Printed Resources and Digital Information: The Future of Coexistence

\author{
March 2-3, 2006 \\ Oklahoma City, Oklahoma
}

\author{
Speakers: \\ Joseph J. Eranin - Ohb State Un'versty \\ Mchael K Euctuand - Unkerety of Calknia, Denaky \\ Dan C. Hazen - Harkad Untersity \\ Fred H. Heath - Untersity of Texas at Austin \\ Karen Hunter - Eksor \\ Joan K Lippinodt - Coeliton h Hswoited Infomaton \\ Bemard F. Feily, Jr. - Csiter for Asesarh Lbrartes. \\ Hohal Sphella - JSTOR HAw York \\ htto/hibrariessou.eduiconference \\ REGISTRATION DEADLINE: February 17, 2006

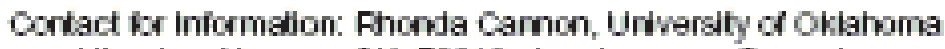 \\ Lbrañes, Nomman, OK 73019 fondasmond hou.eju; \\ Prone: $405-326-2611$
}

